\title{
The Influence of Ad Blockers on the Online Advertising Industry
}

\author{
Tomislav Ivanjko \\ Department of Information and Communication Sciences, \\ Faculty of Humanities and Social Sciences, University of Zagreb \\ Ivana Lučića 3, Zagreb, Croatia \\ tivanjko@ffzg.hr \\ Tanja Bezjak \\ AdCumulus \\ bezjaktanja@gmail.com
}

\begin{abstract}
Summary
Online advertising developed in 1994 as a means of financing website content production, but a constantly decreasing number of ad impressions and a significant rise in ad blocker users have incurred the loss of $30 \%$ of total industry revenue in 2015. However, studies reveal that two-thirds of current ad blocker users would to be willing to turn their blockers off should overall user experience be improved. As marketers continue debating whether the ad block revolution will finish online advertising, this paper presents an alternate viewpoint. It suggests that the rise of the ad block has been beneficial to the industry, because exposing the weaknesses of the current advertising model and the reasons for blocker popularization prompts the damaged model to change. It gathers best practices in advertising and recommendations for creating ads which do not need to be blocked.
\end{abstract}

Key words: online advertising, ad blocking, user experience, banner, ad

\section{Introduction}

Value exchange exists in every community, primal and modern ones alike. Whether it is trading berries for a piece of meat or currency for products and services, it is implied that both sides should obtain value. How did we then begin to feel entitled to go online and get content without any duty to compensate? There is a general expectation that online content should be "free"; at the same time, there is no general understanding that online advertising is what makes it possible (IAB, 2016). Since 1994, websites have sold their media space to finance content production. The online advertising chain is profitable for all its participants; publishers maintain "free" access for users, advertisers promote products and services to obtain new customers, ad networks gather publishers and advertisers, and website visitors use ad impressions as the cur- 
rency for accessing content (Davar, 2013). Evans (2009) suggests that advertising online is potentially the most advanced form of marketing because the use of technology facilitates the meeting of supply and demand. Marketers target relevant marketing messages to objective audiences and direct them towards precise offers, and buyers do not waste time looking at ads that do not interest them.

However, many online users have started using ad blocking software, which prevents the ad from loading by cutting off communication between the ad server delivering ads and the user's computer (Bubna, 2013). It uses predefined blacklists to determine the ad types, publishers, and websites that should be blocked. The website's appearance does not change in the process and there are no blanks left in the content (IAB UK, 2016).

This paper examines the current online advertising model, which provoked the development of the ad blocking software. It explores the main areas of user frustration with online advertising, examines industry standards and trends, and proposes a redefinition of the online advertising model by suggesting the characteristics of ads which would not need to be blocked.

\section{Background research on online advertising}

Such is the importance ad blocking has gained in the last couple of years that it was identified as a global Internet trend in the 2016 Kleiner Perkins Internet Trends Report (PageFair, 2017). A literature review reveals a number of articles contemplating the reasons which have caused the discontent of online users, resulting in 236 million desktop and 380 million mobile active ad blocker users globally, as reported by the Global Adblock Report (PageFair, 2017). To understand what motivates the constantly increasing use of ad blockers and demonstrate that things have not always been this way, the paper will look at the online advertising industry's development.

The online ad which started it all at the end of 20th century was a banner by telecom company AT\&T. The banner was a part of an integrated 2-year TV broadcast campaign (McCambley, 2013), published on $27^{\text {th }}$ October 1994 on HotWired. Turning 23 this year, AT\&T's ad was the standard banner size of $468 \times 60$ pixels (Barker, 2013). The ad copy read "Have you ever clicked here? You will", and an ad click redirected visitors to a landing page containing relevant, entertaining and informative content, and asking users for feedback and improvement suggestions. What started as a means of financing content production (Greenfield, 2014) has since transformed into a 60 billion dollars heavy industry in 2015 alone (PwC, 2015). In the novelty of the World Wide Web and its 14 million most progressive users, 10 thousand of which were HotWired readers (Greenfield, 2014), it is no wonder the first banner ad was an absolute success. Compared to today's average click-through rate of just $0.08 \%$, AT\&T's ad got a whopping $44 \%$ of website visitors' clicks (Barker, 2013). The ad's creative team claims that they aimed to reward the visitor for the click (Greenfiled, 
T. Ivanjko, T. Bezjak, The influence of ad blockers on the online advertising industry

2014), offer useful information, entertain, impress and provide an enjoyable user experience (McCambley, 2013).

And while the value of ads still lies in the sum of clicks and impressions, the number of views and interactions ads get today has decreased significantly since the banner's golden times. There were 3.7 billion Internet users in March 2017 (Internet World Stats, 2017); just as the number of Internet users grew, the number of websites in the online universe increased, too; more and more advertisers were keen to reach out to potential customers through online advertising. The novelty wore off and a coping mechanism for distracting advertising called banner blindness, which entails ignoring the margins of pages where ads are located, kicked in (Shopify, 2016). And whereas ignoring ads is a choice of an individual, using ad blockers implies employing technology which enables the destruction of a business model (Vallade, 2009).

\section{Ad blocker development}

When ignoring ads was no longer enough, ad blocking software emerged as the weapon for ad elimination, costing the online advertising industry $30 \%$ of its annual revenue in 2015 (PageFair \& Adobe, 2015). The founder of the ad blocking software was IT student Henrik Aasted Sørensen from Copenhagen, who built the browser extension AdBlock in 2002. Today, there are more than 100 million users of the most popular ad blocking solution, Eyeo's Adblock Plus (Williams, 2016), and the number is constantly increasing. Reportedly, there were 77 million active desktop ad blocker users in Europe in 2016 (PageFair \& Adobe, 2015) and another 50 million users in the USA (PageFair, 2017).

Although ad blocking stigma tends to victimize only the end users, publishers and advertisers actually bear more significant damage (Davar, 2013). Some portals like Forbes (Morrissey, 2015) have fought back, introducing paywalls to request financial compensation from ad blocker users who refuse to turn it off in order to access content (IAB, 2016a); other websites have implemented software which blocks the ad blocker's functioning (IAB UK, 2016), switching the blocked ad with an alternative one. When IAB realized outsmarting one another was not sustainable in the long term, they did some fact-checking to tackle the problem systematically and discover who blocks ads, why and how to win them back.

The goal of Interactive Advertising Bureau's (2016b) study "Who blocks ads, why and how to win them back" was to determine the demography of ad blocker users, detect the biggest problems with online advertising which prompt ad blocker use, and propose solutions for convincing users to abandon ad blocking software. Out of 1292 respondents, 330 were existing blocker users, 478 had never used it nor intended to start, 260 were former users and 224 expressed affinity to starting to use an ad blocker. The study found men between the ages of 18 do 34 to be both the most common users and the group most likely to stop using it; PageFairs's 2017 Global Adblock Report confirmed it. 
$\mathrm{IAB}$ also dedicated a small portion of their research to mobile users, but as $94 \%$ of global mobile usage of ad blockers occurs in the Asia-Pacific region (PageFair, 2017), and the paper focused mainly on the European and Northern American markets, it was not taken into consideration.

The most important conclusion IAB's study found was hope. Namely, Internet users do not hate all kinds of online advertising (IAB, 2016b). This is backed up by research conducted by Adblock Plus (2016), which revealed that only $25 \%$ of current ad blocker users want all ads eliminated, while the majority is willing to support content production if they are granted satisfactory user experience. Furthermore, US Desktop Adblock Survey Data (PageFair, 2016) confirmed that users do not reject digital advertising in general, but rather disagree with some aspects of its execution.

\section{Main areas of frustration and recommendations}

PageFair's 2017 Global Adblock Report (PageFair, 2017) revealed more than $70 \%$ of online users cannot isolate only one reason for using ad blocking software. Since a number of sources referenced in this article reveal similar problems with online advertising, they were grouped into seven main categories: privacy anxiety, malwertising, user experience, ad format, creativity, relevance and optimization.

Privacy anxiety is the most pronounced objection users hold against online advertising, and a great deal of its notoriousness can be attributed to personal data malpractices (PageFair, 2017). As the industry thrives on user data becoming ever more sophisticated, users and their actions are being tracked and stalked (Evans, 2009) using various technologies which create fear and discomfort (Searls, 2015a). Bits and pieces of data are collected, processed, and mushed together into Big Data with the goal to respond to users' needs accurately. As noble as that cause may sound, data misuse is common, and websites often collect valuable personal data of their visitors in order to sell to third parties (Searls, 2015a), organizations and companies which need user data. Evans (2009) believes educating users about data collecting activity could help minimize their anxiety, because information shortage intensifies it. Besides having data privacy concerns, online users are worried about installing viruses and other malware on their devices by clicking on ads (Bubna, 2013). Users feel safer browsing online when they are protected from ads which might transmit harmful software without approval, and they do not tolerate ads which contain fake exit or download buttons, and pressure users to click on them before proceeding to the wanted page (Davar, 2013).

Consider a typical Internet usage scenario. You turn on the computer either to socialize, browse, look something up or enjoy different content (Shopify, 2016). As you are focusing on your activity, all of a sudden an ad pops up, covering the content and destroying your concentration and flow. Distracted and annoyed, you immediately close the ad window and perceive advertising as a neg- 
T. Ivanjko, T. Bezjak, The influence of ad blockers on the online advertising industry

ative and intrusive occurrence (Brajnik and Gabrielli, 2010). Furthermore, if the same ad keeps popping up over and over again, it is really not that difficult to understand the motivation behind installing ad blockers. The latter can be prevented with frequency capping (PageFair, 2017), which is setting the maximal number of ad occurrences.

Redundancy intensifies irritation, especially with the most hated ad formats. These are interstitial ads which take over the whole page, overlay ads which cover the page content, pop-ups and pop-unders which appear out of nowhere, pre-roll videos which cause video abandonment (Vallade, 2009), ads heavy on visual effects which distract the user from viewing content, scroll-down ads which follow you as you scroll down the page and rich-media ads which consume huge portions of your data plan and slow down the page load time, blinking and playing audio and video automatically (IAB, 2016b) (IAB UK, 2016). Therefore, IAB (2016) suggests ads should be limited in size and dimensions, have a fixed position on the page, and only load once the web visitor scrolls to the part of the page where the ad is located.

Getting the user to view the ad is the easy part; getting them to click on it is significantly more demanding. If you would not click an ad, why would your audience? It seems advertisers have forgotten an important lesson AT\&T's creative team tried to teach; offer useful information, entertain, impress and give online users an enjoyable experience (McCambley, 2013). A lot more thought should be given to engaging the users, and following the three Is recipe might be useful; make your ad inviting, interesting and innovative and top it off with valuable content (Shopify, 2016). Ads which have irrelevant content (Brajnik and Gabrielli, 2010) and lack connection to users' interests are advertising money poured down the drain. Some online users reacted positively to the possibility to define the fields of interest for which they wish to receive ads. That way, the user gets precisely targeted ads, advertisers promote directly to their target customers and publishers get ad interactions. Furthermore, users should be given the possibility to provide feedback for the ads they see, rating them positively or negatively, and refining their preferences even further. Finally, all ads should be continually tested, audience response tracked and measured, and analytic tools used to monitor key performance indicators and optimize if necessary (Shopify, 2016).

\section{Standards which propose solutions to the blocked Web}

Several notable proposals and initiatives by respectable industry institutions to get online advertising malpractices under control stand out, with the focus on introducing methodical changes and standardizing the online advertising model. Such is the LEAN ads standard, which was first presented to IAB's "Who blocks ads" study respondents as one solution against bad advertising and ad blocking. It was applauded and praised by the majority of respondents, who said they would turn off their ad blockers if online ads fulfilled the four main pre- 
requisites implied in $L E A N$. According to the standard, ads should be light in order to load fast and not consume too much data, encrypted to secure user data and protect users from privacy breaches, Ad Choice supported to let visitors control information regarding their interests, and non-invasive in their appearance, not do disrupt user experience or be distractive (IAB, 2016b).

And while $L E A N$ caters to end users, IAB's $D E A L$ standard appeals to the other important players in the game; the publishers. It promotes initiating dialogue with the user who visits a website with an active ad blocker. In such event, the standard suggests undertaking the following steps. When ad blocker usage is detected, the visitor should be educated about the "value exchange", namely informed that advertising finances the website's content production. Then, the visitor should kindly be asked to disable the software, temporarily or permanently, in order to access the content they wish to view. Finally, the publisher should either limit access to content or let the visitor view it, depending on the visitor's decision to disable the software. However, PageFair's 2017 report has deemed this approach ineffective, stating that $74 \%$ of users who encounter an adblock wall simply abandon the website which requires the blocking software to be disabled, with the exception of content which cannot be found anywhere else (PageFair, 2017).

Acceptable Ads initiative is the most controversial solution proposal, as it was introduced in 2011 by the most popular ad blocking software company itself (Solon, 2016). Adblock Plus started the initiative as an attempt to bring the online advertising industry back into balance. Aware that not all ads are bad, they gave online users the possibility to only block ads which threatened pleasant user experience, and otherwise support advertisers whose ads were deemed acceptable by a proposed set of guidelines, pertaining mainly to ad content, positioning, and dimensions (Adblock Plus, 2016). The fact that an ad blocking company itself attempted to find a way to unblock the Web speaks about the importance of the role which online advertising plays in the creation and consumption of the content available online.

\section{Trends and the future of online advertising in the context of ad blocking}

As notorious as online advertising has become nowadays and despite the fact that, statistically, a mere $8 \%$ of total Internet users account for $85 \%$ of all banner clicks (Morrissey, 2013), recent data revealed that the static banner ad is still the preferred ad format among users (PageFair, 2017). Its click-through rate recorded the lowest point in 2008, after which it stabilized around $0.04 \%$ (Morrissey, 2013).

However, ad serving technology has advanced, offering innovative possibilities for segmenting audiences and targeting users precisely (Oberoi, 2013). As the technology evolves further, much attention is given to revenue maximization 
T. Ivanjko, T. Bezjak, The influence of ad blockers on the online advertising industry

and not enough to content optimization. Programmatic advertising, which is the automated buying and selling of advertising space, is quickly gaining popularity and threatening to become the weapon to direct existing problematic ads to larger audiences (McCambley, 2013). On the other hand, MacDonald (2015) insists that the best way to get consumers to voluntarily engage with advertisements is not to make ads at all.

Instead, she suggests attracting visitors' attention with useful content, which is exactly what advertisers have been doing on Facebook. Although its primary purpose was socializing, the fact that $20 \%$ of world population created profiles has turned Facebook into an advertising super machine with approval to access end users' personal data, interests, and affinities (Oberoi, 2013). Its powerful tools are impossible-to-block in-feed ads and a very comprehensive analytics and efficiency reporting system, allowing constant campaign optimization for maximum performance. After all, social platforms are where we spend our free time nowadays, and relevant ads for products and services we have expressed our preference for might be the right direction to go.

Due to the fact that many users ignore traditional ad formats but focus on content, Ming \& Yazdanifard (2014) praise native ads, which mimic the appearance and style of the page they are located within. However, their intention is not to deceive online users; although they look like editorial pieces, they are clearly indicated as ads and may only contain one-third of advertising content. Among preferred ad formats, native ads have been graded neutral by online users (PageFair, 2017).

\section{The new advertising model}

Ad blocking poses a serious threat to destroying the proper functioning of the advertising-financed value exchange powering "free Internet", i.e. users' privilege to access online content for free. This paper gathers the main areas of user frustration, the standards proposed by industry influencers, and the marketing strategies trending on the advertising market, summarizes them into a proposal for the redefinition of the online advertising model and gives recommendations for creating ads which do not need to be blocked.

Table 1: Key aspects of the redefined model of online advertising

\begin{tabular}{|l|l|}
\hline \multicolumn{1}{|c|}{ Current model } & \multicolumn{1}{c|}{ Redefined model } \\
\hline Privacy anxiety & Data safety \\
\hline Revenue maximization & Content optimization \\
\hline Unpredictable ad formats & User-approved non-invasive ads \\
\hline Interruption and redundancy & Enhanced flow and frequency capping \\
\hline Banner blindness & Native advertising \\
\hline
\end{tabular}

As most respondents of IAB's (2016) and Page Fair's (2017) research expressed, data safety is the primary concern regarding online advertising. It should be secured with encrypted ads, ensuring no malware gets in the way and 
no private information leaks. This has already been attempted with filters such as Acceptable Ads, but marketers should also consider users' preferences and enable their feedback in the future. When users have more control, there is less room for worrying, doubting and needing defence. Furthermore, instead of refining the ad serving technology to achieve revenue maximization, marketers should focus more on what they are serving. The answer to optimizing the quality of ads might lie in the three approaches which have been trending on the online advertising scene recently: social networks as the platform, content marketing as the strategy (MacDonald, 2015), and native advertising as the format (Ming and Yazdanifard, 2014). The consequences of banner blindness should not be fought with the use of irritable and unpredictable ad formats. Marketers should abandon pop-ups and replace them with non-invasive, user-approved static banners or native ad formats, with limited frequency capping to prevent overwhelming visitors. Finally, users' clicks should be attracted with quality, useful and relevant content (MacDonald, 2015) and original design.

\section{Conclusion}

Marketers have overwhelmed online users, who have in turn responded by eliminating ads by using ad blocking technology. Since most of the content production available online is financed with advertising revenue, the right to "free Internet", which most World Wide Web users take for granted, is at stake. With the goal of introducing methodical changes to repair the damaged online advertising model, IAB carried out a study which revealed two-thirds of online users are willing to abandon the blocker if user experience improves.

Based on IAB's study, a number of industry-relevant sources and advertising best practices, this article provides recommendations for the redefinition of the online advertising model. If the focus is placed on data safety, uninterrupted user experience and quality creative content in the future, there is a promise of an improved sustainable solution which will allow the continuation of the value exchange powering the Web as we know it.

\section{References}

Adblock Plus. Allowing Acceptable Ads in Adblock Plus. https://adblockplus.org/acceptable-ads $(2017 / 04 / 10)$

Barker, Dan. The First Ever Banner Ad (\& How it Performs Today). 2013/10/30. http://barker.co.uk/banner (2017/04/13)

Brajnik, Giorgio; Gabrielli, Silvia. A Review of Online Advertising Effects on the User Experience. // Journal of Human-Computer Interaction. 26 (2010), 971-997.

Bubna, Josiah. The Ethics of Adblock. 2013/05/06. http://bubnaphotography.com/josiah/writing/TheEthicsofAdblock.pdf (2017/04/16)

Evans, David S. The Online Advertising Industry: Economics, Evolution, and Privacy. // Journal of Economic Perspectives. 23 (2009), 3; 37-60.

Greenfield, Rebecca. The Trailblaizing, Candy-Colored History of The Online Banner Ad. 2014/10/27. https://www.fastcompany.com/3037484/most-creative-people/the-trailblazingcandy-colored-history-of-the-online-banner-ad (2017/04/10) 
T. Ivanjko, T. Bezjak, The influence of ad blockers on the online advertising industry

IAB. Publishers Making DEALs to Battle Ad Blocking in the U.S. and in Europe. 2016/04/25. https://www.iab.com/news/publishers-making-deals-to-battle-ad-blocking/ (2017/03/23)

IAB. Ad Blocking: Who Blocks Ads, Why and How to Win Them Back. June 2016. http://www.iab.com/wp-content/uploads/2016/07/IAB-Ad-Blocking-2016-Who-Blocks-AdsWhy-and-How-to-Win-Them-Back.pdf (2017/04/16)

Internet Advertising Bureau UK. AdBlocking FAQs 2016. March 2016. https:/www.iabuk.net/sites/default/files/Ad\%20blocking\%20FAQ\%20March\%202016.pdf $(2017 / 04 / 29)$

Internet World Stats. Internet Usage Statistics: World Internet Users and 2017 Population Stats. 2017/03/31. http://www.internetworldstats.com/stats.htm (2017/04/16)

MacDonald, Muriel. Better than Banner Ads: Smart Ways to Spend Your Ad Dollars in 2015. 2015/01/12. http://www.tintup.com/blog/better-than-banner-ads-smart-ways-spend-addollars-2015-muriel-macdonald/ (2017/04/29)

McCambley, Joe. The First Ever Banner Ad: Why Did It Work So Well? // The Guardian, [online]. 2013/12/12. https://www.theguardian.com/media-network/media-networkblog/2013/dec/12/first-ever-banner-ad-advertising (2017/04/10)

Ming, Wong Qi; Yazdanifard, Rashad. Native Advertising and its Effects on Online Advertising. // Global Journal of Human-Social Science (E). 14 (2014), 8; 11-14.

Morrissey, Brian. 15 Alarming Stats About Banner Ads. 2013/03/21. https://digiday.com/publishers/15-alarming-stats-about-banner-ads/ (2017/04/16)

Morrissey, Brian. Forbes Starts Blocking Ad-Block Users. 2015/12/21. http://digiday.com/publishers/forbes-ad-blocking/ (2017/04/29)

Oberoi, Ankit. The History of Online Advertising. 2013/07/03. http://adpushup.com/blog/thehistory-of-online-advertising/ (2017/04/16)

PageFair and Adobe. The Cost of Ad Blocking: Ad Blocking Report. 2015. https://downloads.pagefair.com/wp-content/uploads/2016/05/2015_reportthe cost_of_ad_blocking.pdf (2017/04/10)

PageFair. Adblocking Goes Mobile: 2016 Mobile Adblocking Report. November 2016. https://pagefair.com/wp-content/uploads/2016/05/Adblocking-Goes-Mobile.pdf (2017/03/23)

PageFair. The State of the Blocked Web: 2017 Global Adblock Report. 2017/02/01. https://pagefair.com/downloads/2017/01/PageFair-2017-Adblock-Report.pdf (2017/04/16)

PwC. IAB Internet Advertising Revenue Report: 2015 Full Year Results. April 2016. https://www.iab.com/wp-content/uploads/2016/04/IAB-Internet-Advertising-RevenueReport-FY-2015.pdf (2017/03/23)

Searls, Doc. How Will the Big Data Craze Play Out? // Linux Journal, [online]. 2015/11/04. http://www.linuxjournal.com/content/how-will-big-data-craze-play-out (2017/04/29)

Sharetrough. Native Ads vs Display Ads. 2013. http://www.sharethrough.com/resources/nativeads-vs-display-ads/ (2017/03/10)

Shopify. 50 Ways to Make Your First Sale: Buy Banner Ads (Chapter 27). 2016. https://www.shopify.com/guides/make-your-first-ecommerce-sale/banner-ads (2017/04/13)

Solon, Olivia. Adblock Plus Launching Platform to Sell 'Acceptable' Ads. // The Guardian, [online]. 2016/09/13. https://www.theguardian.com/business/2016/sep/13/adblock-pluslaunching-platform-to-sell-acceptable-ads (2017/04/16)

Target Marketing. Consumers Prefer Targeted, Relevant Online Advertising in Exchange for Trade-Offs. 2010/07/08. http://www.targetmarketingmag.com/article/consumers-prefertargeted-relevant-online-advertising-in-exchange-trade-offs/ (2017/03/10)

Vallade, Jilian. Adblock Plus and the Legal Implications of Online Commercial-Skipping. // Rutgers Law Review. 61 (2009), 3; 823-853.

Williams, Ben. Adblock Plus and (a Little) More: 100 Million Users, 100 Million Thank-yous. 2016/05/09. https://adblockplus.org/blog/100-million-users-100-million-thank-yous (2017/04/13) 